\title{
ESTÁGIO CURRICULAR: POSSIBILIDADE DE CONSTRUÇÃO DO HABITUS DOCENTE
}

\author{
Mari Clair Moro Nascimento ${ }^{1}$ \\ https://orcid.org/0000-0002-8120-7841 \\ Edilaine Vagula² \\ https://orcid.org/0000-0003-1992-9680
}

RESUMO: este texto, realizado a partir de pesquisa bibliográfica, visa a suscitar reflexões acerca da formação do habitus docente no estágio curricular. Para isso, ressalta a função da escola na construção do sujeito, apresentando suas incumbências no aspecto pedagógico e no social, visto a necessidade de ampliar o capital cultural dos estudantes provenientes de classes sociais menos favorecidas. Destaca a relevância de os cursos de formação de professores oportunizarem aos estagiários a construção do habitus docente, por meio de parcerias entre escolas e instituições formadoras, por ser uma das limitações a serem superadas na formação inicial. Conclui-se que a troca dialógica, as atividades colaborativas e estratégias interativas interferem na construção da identidade dos professores em formação e favorecem a construção do habitus docente.

PALAVRAS- CHAVE: estágio curricular, habitus docente, formação de professores.

\section{CURRICULAR INTERNSHIP: POSSIBILITIES TO CONSTRUCT THE TEACHING HABITUS}

ABSTRACT: the present article, based on bibliographical research, expects to stimulate reflections on the formation of teaching habitus in the curricular internship.

\footnotetext{
${ }^{1}$ Doutora em Educação. Docente no Ensino Superior.Universidade Estadual de Londrina - UEL.Universidade Norte do Paraná - UNOPAR.Londrina- Paraná. mariclairmoro@hotmail.com

${ }^{2}$ Doutora em Educação. Docente no Ensino Superior. Universidade Estadual de Londrina - UEL.LondrinaParaná.edialinevagula@yahoo.com.br
} 
Therefore, it emphasizes the role of the school in the construction of the subject, presenting its duties on pedagogical and social aspects, considering the need to increase the cultural capital of students from less favoured social classes. Emphasizes the importance of training courses for teachers in order to give trainees the opportunity to construct the teaching habitus, through partnerships between schools and training institutions, being it one of the limitations to overcome in initial training. The conclusion is that the dialogic exchange, collaborative activities and interactive strategies interfere in the construction of the identity of the teachers in formation and favor the construction of the teaching habitus.

KEYWORDS: curricular internship, teaching habitus, teacher training.

\section{PRÁCTICAS CURRICULARES: POSIBILIDADES DE CONSTRUCCIÓN DEL HABITUS DOCENTE}

Resumen: este texto, realizado a partir de investigación bibliográfica, tiene por objeto suscitar reflexiones acerca de la formación del habitus docente en las prácticas curriculares. Con este fin, resalta la función de la escuela en la construcción del sujeto, presentando sus funciones en el aspecto pedagógico y en el social, visto la necesidad de ampliar el capital cultural de los estudiantes provenientes de clases sociales menos favorecidas. Destaca la relevancia de los cursos de formación de profesores posibilitaren a los becarios la construcción del habitus docente, por medio de asociaciones entre escuelas e instituciones formadoras, por ser una de las limitaciones a ser superadas en la formación inicial. Se concluye que el cambio dialógico, las actividades colaborativas y estrategias interactivas interfieren en la construcción de la identidad de los profesores en formación y favorecen la construcción del habitus docente.

PALABRAS CLAVE: prácticas curriculares, habitus docente, formación de profesores. 
Introdução

A profissionalização docente conforme é concebida na atualidade é decorrente do século XV (ARIÈS, 1978). Desde então, diversas reformas foram instituídas na formação de professores, mas conforme anuncia Saviani (2011) nenhuma delas, até o presente momento, atenderam às necessidades do nosso país, existindo, portanto, alguns desafios a serem superados. Entre os desafios apontados por Saviani (2011) como necessários de superação, na formação de professores, neste texto, a atenção se volta para aquele que aponta a necessidade de estreitar a relação entre as instituições de formação e as escolas, porque segundo Saviani (2011) o processo formativo dos professores e o redimensionamento do estágio deve acontecer a partir do modo de funcionamento das escolas.

Diante disso, este estudo, realizado a partir de pesquisa bibliográfica e tendo por objetivo conhecer ações realizadas no estágio curricular ${ }^{3}$ para promover a construção do habitus docente, apresenta inicialmente a função da escola na construção do sujeito, momento em que são destacadas suas incumbências no aspecto pedagógico SAVIANI, 1995; VIEIRA; ALMEIDA, 200-; RAMOS; LEITE; FILHO, 2012) e no social (ARROYO, 1986; VIEIRA; ALMEIDA, 200-), tendo em vista, ampliar, especialmente, o capital cultural dos estudantes provenientes de classes sociais menos favorecidas, para que haja uma mudança de habitus (Bourdieu, 1998). Destaca-se também a necessidade de os cursos de formação proporcionarem aos futuros professores a compreensão de sua função, podendo o estágio curricular ser o espaço que oportunize a construção do habitus docente, a partir de parcerias entre as instituições formadoras e a escola. Visando a atingir o objetivo desse estudo, é apresentada a pesquisa de Sarti (2013), por relatar uma parceria que tem acontecido entre o curso de Pedagogia da UNESP de Rio Claro, estagiários e professores com experiência no magistério, desde o ano de 2006, a qual tem oportunizado ganhos a todos os envolvidos no processo.

\section{Metodologia}

A escolha por realizar este estudo a partir de pesquisa bibliográfica se deu por ser relevante conhecer experiências que já têm sido realizados no

\footnotetext{
${ }^{3} \mathrm{O}$ termo estágio curricular, utilizado no decorrer do texto, e estágio supervisionado, apresentado no estudo de Sarti (2013), referem-se ao mesmo aspecto, momento em que os futuros professores, ainda na formação inicial, têm para conhecer seu campo profissional de atuação.
} 
estágio curricular e que podem favorecer a construção do habitus docente, visto que essa abordagem se embasa em materiais que já existem acerca do objeto de estudo (GIL, 999). Assim, justifica-se o embasamento do referido estudo na pesquisa bibliográfica, porque, conforme afirma Gil (1999), toda pesquisa busca uma contribuição ou uma resposta ao problema proposto e saber de experiências que já deram certo no estágio curricular, no que se refere à construção do habitus docente, favorece as instituições de ensino superior a pensarem sobre formas de ressignificar o cotidiano do seu estágio curricular, tendo em vista estabelecer melhorias na formação inicial para a docência.

Diante do exposto, este texto apresenta fundamentos teóricos de livros e artigos científicos, expressando o que dizem estudiosos do tema acerca da função social da escola na construção do sujeito e a experiência efetivada no estágio curricular descrita no estudo de Sarti (2013), por se efetivar mediante uma parceria entre os estagiários e os professores já atuantes, sendo atribuído a esses últimos, por estarem no exercício da profissão, a função de agentes de formação. A escolha por destacar essa configuração de estágio curricular não desqualifica outros modelos que se concretizam nas diversas instituições de ensino superior, porque a intenção é fomentar junto aos envolvidos neste momento da formação inicial reflexões sobre as diversas possibilidades da sua efetivação, sendo a pesquisa bibliográfica uma forma de conhecê-las, visto que ela proporciona saber o que já se tem feito na área, ou seja, uma pesquisa detalhada proporcionará acesso às diversas possibilidades de organizar o estágio curricular para que ele favoreça a construção do habitus docente.

\section{A função da escola na construção do sujeito}

Compreender a função da escola na construção do sujeito demandou esclarecer suas incumbências em termos pedagógicos (SAVIANI, 1995; VIEIRA; ALMEIDA, 200-; RAMOS; LEITE; FILHO, 2012) e sociais (ARROYO, 1986; VIEIRA; ALMEIDA, 200-). Ambas as funções, pedagógica e social, consolidam-se a partir dos processos de ensinar, pelos professores, e de aprender, pelos alunos, estando assim relacionadas, porque o entendimento dos conteúdos das diversas áreas do conhecimento, função pedagógica, precisa favorecer a construção da consciência crítica na formação do sujeito, função social.

Sobre a função pedagógica da escola, Vieira e Almeida (200-, p. 05) dizem que essa se refere aos "[...] conteúdos básicos e clássicos que farão parte do fazer pedagógico das salas de aula.", sendo que a função social "[...] consiste em promover mudanças nos sujeitos e na realidade." Frente ao exposto, 
percebe-se que, na escola, "[...] não existe espaço apenas para a transmissão do conteúdo por si só, do conteúdo pelo conteúdo; é necessário trabalhar as dimensões pessoais, sociais e culturais do sujeito." (VIEIRA; ALMEIDA, 200-, p. 06), porque os conteúdos nada mais são do que "[...] os mediadores do conhecimento e da competência do educando para compreender o mundo." (RODRIGUES, 1992, p. 80). Frente ao exposto, cabe recorrer a Azanha (1998, p. 40) quando explica que "[...] o professor de latim precisa compreender que antes de ser professor de latim ele precisa ser professor, isto é, ele é membro de uma comunidade escolar com objetivos e um alcance social que vão além do ensino de qualquer disciplina". Ou seja, ser professor é muito mais do que verbalizar os conteúdos a serem apenas memorizados pelos alunos, porque o ensino das normas da língua, do fato histórico, da localização geográfica, entre outros conteúdos das diversificadas áreas do conhecimento, precisa oportunizar ao educando o entendimento do mundo. De acordo com Ramos, Leite e Silva (2012), quando a escola esquiva-se da função de oportunizar ao educando o desvelamento da sua realidade, rouba-lhe a chance da busca pela superação das condições sociais impostas. Sobre os conteúdos, Saviani (1995) diz que são essenciais, porque sem eles não existe aprendizagem. Segundo ele "[...] nós precisaríamos defender o aprimoramento exatamente do ensino destinado às camadas populares." (SAVIANI, 1995, p. 65).

Diante disso, nota-se a importância de munir de conhecimentos todos os estudantes, em especial aqueles provenientes das camadas populares, por possuírem menor acesso aos saberes acumulados historicamente, em função do capital cultural ${ }^{4}$ recebido no contato com os grupos com os quais convivem, em especial com o familiar. Conforme anuncia Bourdieu (1998, p. 53),

[...] para que sejam favorecidos os mais favorecidos e desfavorecidos, é necessário e suficiente que a escola ignore, no âmbito dos conteúdos do ensino que transmite, dos métodos e técnicas de transmissão e dos critérios de avaliação, as desigualdades culturais entre as crianças das diferentes classes sociais. Em outras palavras, tratando todos os educandos, por mais desiguais que sejam eles de fato, como iguais em direitos e deveres, o sistema escolar é levado a dar sua sanção às desigualdades iniciais diante da cultura.

\footnotetext{
${ }^{4}$ Bourdieu (1998) apresenta o capital cultural em três estados: incorporado, objetivado e institucionalizado. Incorporado é aquele proveniente das relações que o sujeito estabelece com o mundo, incluindo a herança familiar, que acaba por facilitar o aprendizado dos conteúdos e códigos escolares. Objetivado se concretiza em objetos materiais como: quadros, pinturas, livros etc, aspecto que demanda ter capital econômico. Institucionalizado é representado a partir dos títulos escolares, diplomas.
} 
Então, de acordo com Bourdieu (1998), tratar a desigualdade com igualdade é uma forma de alavancar o capital cultural dos estudantes provenientes de classes sociais menos favorecidas. Assim sendo, nota-se que é preciso voltar os olhares para a diversidade de alunos existente na sala de aula, porque se torna essencial conhecer o capital cultural que possuem os estudantes. No entanto, não cabe tal reconhecimento para tratar com piedade ou excluir aqueles sujeitos cujo capital cultural se diferencia do priorizado na escola, mas para possibilitar a sua ampliação, porque segundo Nogueira e Nogueira (2002), Bourdieu considera o capital cultural, sobretudo, na sua forma incorporada, impactante no destino escolar dos sujeitos.

Diante de tal apontamento cabe atentar à expressão "trabalhar com a realidade do aluno", muito verbalizada por professores já atuantes, pois se sabe que é importante iniciar os estudos a partir do que os alunos já conhecem, mas para ampliar os horizontes e a visão de análise dos mesmos, no intuito de que possam tornar as coisas diferentes (BAUMAN, 2005). De acordo com Freire (1987), é preciso partir daquilo que o aluno já sabe, tendo em vista ampliar sua visão de mundo, o que só se concretiza a partir de uma educação libertadora, aquela que favorece ao aluno, reflexivamente, alargar seus conhecimentos. Então, quando no processo da alfabetização Freire (1987) propõe a utilização de palavras geradoras, é porque essas compõem o universo de conhecimento dos alunos e conhecê-las em sua essência oportuniza uma aprendizagem mais contextualizada, consciente e, sobretudo, política, porque a partir da compreensão crítica da palavra o sujeito estará apreendendo também o mundo.

Nesta perspectiva, parte-se sim do que o aluno já sabe, mas para aumentar o capital cultural e a visão de mundo do mesmo, porque segundo Moreira e Candau (2003, p. 23), a escola, enquanto instituição construída historicamente tem como função social "[...] transmitir cultura, oferecer às novas gerações o que de mais significativo culturalmente produziu a humanidade". Segundo Bourdieu (1998, p. 61),

[...] somente uma instituição cuja ação específica fosse transmitir ao maior número possível de pessoas, pelo aprendizado e pelo exercício, as atitudes e aptidões que fazem o homem" culto", poderia compensar (pelo menos parcialmente) as desvantagens daqueles que não encontram em seu meio familiar a incitação à política cultura.

Frente a isso, cabe recorrer a Arroyo (1986), quando fala sobre a or- 
ganização do sistema escolar brasileiro, pois ele afirma que há, em curso, um projeto que não atende à classe popular, sendo essencial a "[...] redefinição desse projeto a serviço de interesses de classe, e não a serviço da melhor sorte e da ascensão de alguns indivíduos." (p. 19), porque o saber requerido pela escola acaba sendo muito diferente daquele que os alunos de classes menos favorecidas possuem. Assim, em vez de a escola acolher as deficiências culturais e agir para supri-las, acaba por acentuar os alunos que possuem melhor desempenho, excluindo aqueles que não alcançam o sucesso, ficando esses últimos responsabilizados pelo próprio fracasso.

Sobre o sucesso e fracasso escolar, Bourdieu e Passeron (1964) dizem que os estudantes de classes sociais mais favorecidas alcançam melhores resultados escolares porque, na maioria das vezes, já possuem familiaridade com o que é abordado neste espaço, não sendo o sucesso ou o fracasso escolar uma decorrência de dons, mas proveniente do capital cultural, até então recebido pelo estudante. Sobre isso, Hidalgo (2014, p. 202) diz que,

\begin{abstract}
Nesse contexto, o capital cultural dos educandos proveniente de sua classe social de origem influirá no sucesso escolar, na medida em que o ethos do sistema educacional, em que está inserido, aproxima-se da cultura elitista e afasta-se da cultura das classes menos favorecidas, revelando, portanto, um contexto marcado pela exclusão em cujo sistema ecoa o privilégio da classe dominante.
\end{abstract}

Nesta mesma concepção, Pereira e Andrade (2007, p. 56) afirmam que "[...] a escola exclui, de maneira explícita, aqueles que não se enquadram ao padrão por ela determinado, quando usa do discurso persuasivo no qual os dons naturais justificam os rendimentos diferenciais dos alunos na escola".

Sobre a organização da escola, Nogueira e Nogueira (2002) dizem que a maneira como ela tem se organizado proporciona às crianças oriundas de classes culturalmente favorecidas uma espécie de continuação da educação recebida na família, sendo que para as demais crianças tudo é muito diferente e até ameaçador, porque elas ingressam em um mundo muito diferente do vivenciado até então. No que se refere ao capital cultural que possuem os alunos proveniente de famílias mais favorecidas culturalmente, as pesquisadoras dizem que "A posse de capital cultural favoreceria o êxito escolar, em segundo lugar, porque propiciaria um melhor desempenho nos processos formais e informais de avaliação." (p. 21).

Frente ao exposto, é possível afirmar que ampliar o capital cultural dos 
estudantes de classes sociais menos favorecidas é uma das funções sociais da escola e isso só pode acontecer quando se oportuniza a esses alunos ampliarem seus conhecimentos, porque "[...] ao omitir de fornecer a todos [os alunos] o que alguns recebem da família, o sistema escolar perpetua e sanciona as desigualdades iniciais." (BOURDIEU, 2003, p. 108). Ou seja,

Não recebendo de suas famílias nada que lhes possa servir em sua atividade escolar, a não ser uma espécie de boa vontade cultural vazia, os filhos das classes médias são forçados a tudo esperar e a tudo receber da escola, e sujeitos, ainda por cima, a serem repreendidos pela escola por suas condutas por demais "escolares". (BOURDIEU, 1998, p. 55).

Assim sendo, é preciso compreender que o desempenho do sujeito na escola não decorre de ter ou não dons, mas da sua origem social porque é essa uma das instâncias que oportuniza a aquisição do capital cultural (NOGUEIRA; NOGUEIRA, 2002),

\begin{abstract}
Na realidade, cada família transmite a seus filhos, mais por vias indiretas que diretas, um certo capital cultural e um certo ethos, sistema de valores implícitos e profundamente interiorizados, que contribui para definir, entre coisas, atitudes face ao capital cultural e à instituição escolar. A herança cultural que difere, sob os dois aspectos, segundo as classes sociais, é a responsável pela diferença inicial das crianças diante da experiência escolar e, consequentemente, pelas taxas de êxito. (BOURDIEU, 1998, p. 41-42).
\end{abstract}

Então, sob a análise de Bourdieu (1998), na escola, o fracasso dos alunos de classes sociais menos favorecidas, bem como os méritos daqueles provenientes daquelas mais abastadas, provêm do capital cultural recebido no seio familiar.

Sobre a forma como acontece o processo de ensino na escola, Nogueira e Nogueira (2003, p. 38) explicam que,

A comunicação pedagógica, tal como se dá tradicionalmente na escola, exige de forma implícita, para o seu pleno aproveitamento, o domínio prévio de um conjunto de habilidades e referências culturais e linguísticas que apenas os membros das classes mais cultivadas [da cultura de elite] possuiriam. Os professores transmitem sua mensagem igualmente a todos os alunos, como se todos tivessem os mesmos instrumentos de decodificação. 
O que fora anunciado por Nogueira e Nogueira (2003) possibilita afirmar que a maneira como os professores conduzem suas práticas pedagógicas não têm oportunizado aos alunos, que possuem um nível diferente de capital cultural exigido pela escola, entenderem o que tem sido ensinado, aspecto que acaba por favorecer apenas os alunos que já possuem o conjunto de habilidades requeridas por este modelo de escola,

Desta forma, a escola, que deveria ser um ambiente de acoIhimento e de promoção do aluno, torna-se um ambiente de estranhamento e de violência simbólica ${ }^{5}$ para aqueles oriundos de classes sociais desfavorecidas, pois estes estão submetidos a uma condição que não Ihes é familiar. (CARVALHO, 2012, p. 3).

Então, atentar para a forma como se concretizam as práticas pedagógicas na sala de aula é essencial, porque essas precisam atender ao contexto de cada escola (AZANHA, 1998). Então, de acordo com Azanha (1998) deve-se visar à melhoria do ensino da escola, enquanto instituição social e não do professor isolado, porque "A escola, ou melhor, o mundo escolar é uma entidade coletiva, situada num certo contexto, com práticas convicções, saberes que se entrelaçam numa história própria em permanente mudança." (p. 41).

Nesta visão, ressalta-se a importância de atentar para o capital cultural dos estudantes que compõem a escola, no intuito de que os professores tenham práticas pedagógicas que proporcionem a sua ampliação. Segundo Patto (2004, p. 64),

[...] a escola pública fundamental de hoje dá continuidade à negação do direito à formação escolar a enorme parcela das crianças e jovens brasileiros. No passado, a maioria estava fora da escola; hoje, a maioria está dentro dela, mas agora vítima, como nunca, da "ilusão de inclusão". [...] abre-se mão de sua identidade como instituição que tem por fim garantir o acesso de todos aos conhecimentos que lhe cabe transmitir.

Então, não basta às crianças estarem na instituição escolar, sendo essencial proporcionar-lhes a melhoria dos saberes adquiridos até então, ou

\footnotetext{
${ }^{5}$ Bourdieu (2003b, p. 7-8) anuncia a violência simbólica como uma "[...] violência suave, insensível, invisível a suas próprias vítimas, que se exerce essencialmente pelas vias puramente simbólicas da comunicação e do conhecimento, ou, mais precisamente, do desconhecimento, do reconhecimento ou, em última instância, do sentimento." Na escola ela acontece, porque a forma como ela se organiza atende aos interesses hegemônicos, por meio de uma construção sócio-histórica.
} 
seja, a ampliação do capital cultural. De acordo com Bourdieu (1998, p. 75), “O capital cultural é um ter que se tornou ser, uma propriedade que se fez corpo e tornou-se parte integrante da 'pessoa', um habitus".

Bourdieu (1992, p. 108), define habitus como "Sendo produto da história, é um sistema de disposição aberto, que é incessantemente confrontado por experiências novas e, assim, incessantemente afetado por elas." É produzido em "[...] condicionamentos e trajetórias diferentes, em espaços distintos como a família, a escola, o trabalho, os grupos de amigos e/ ou a cultura de massa." (SETTON, 2002, p. 65). Nogueira e Nogueira (2002, p. 21) exemplificam a relação entre capital cultural e habitus no contexto escolar:

Cobra-se que os alunos tenham um estilo elegante de falar, de escrever e até mesmo de se comportar; que sejam intelectualmente curiosos, interessados e disciplinados; que saibam cumprir adequadamente as regras da "boa educação". Essas exigências só podem ser plenamente atendidas por quem foi previamente (na família) socializado nesses mesmos valores.

O habitus evidencia a posição que o sujeito ocupa na estrutura social, porque ele acaba por ter ações em conformidade com o histórico da classe social a qual pertence. No entanto, tais disposições construídas não são imutáveis (BOUDIEU, 1992), podem ser modificadas quando confrontadas com experiências novas, conforme também anuncia Setton (2002, p. 67),

\begin{abstract}
Reitero a necessidade de considerar o habitus um sistema flexível de disposição, não apenas resultado da sedimentação de uma vivência nas instituições sociais tradicionais, mas um sistema em construção, em constante mutação e, portanto, adaptável aos estímulos do mundo moderno: um habitus como trajetória, mediação do passado e do presente; habitus como história sendo feita; habitus como expressão de uma identidade social em construção.
\end{abstract}

Ao atentar para o anunciado por Bourdieu (1992) e Setton (2002), percebe-se que o habitus, reconhecido como uma identidade social em construção pode ser transformado,

Assim abre-se a possibilidade de pensar o surgimento de um outro sujeito social, abre-se espaço para se pensar a constitui-

\footnotetext{
${ }^{6}$ Entende-se por habitus, um conjunto de disposições que orientam as ações, gostos e preferências do sujeito, sendo, portanto, proveniente do ambiente social em que se insere o sujeito, o resultado de uma bagagem herdada socialmente (BOURDIEU, 1992).
} 
ção da identidade social do indivíduo moderno a partir de um habitus híbrido, construído não apenas como expressão de um sentido prático incorporado e posto em prática de maneira "automática", mas uma memória em ação e construção. (SETTON, 2002, p. 66).

Então, se a escola der a todos os estudantes a oportunidade de acesso aos bens culturais acumulados historicamente, poderá favorecer a ampliação do capital cultural e mudança do habitus dos estudantes provenientes de classes menos favorecidas. No entanto, no que se refere às práticas dos professores, cabe recorrer ao exposto por Hidalgo (2014, p. 201), quando afirma que "Um trabalho pedagógico pode apresentar duas diferentes maneiras de inculcação: a que visa modificar completamente um habitus por outro (conversão ou transformação) e a que visa manter o habitus familiar.", porque a mudança de habitus só irá acontecer se a escola oportunizar momentos para a sua transformação. Para isso é preciso lembrar que cada escola tem as suas peculiaridades, pois "[...] a instituição escola pública é uma diversidade, não é uma unidade." (AZANHA, 1998, p. 37), sendo essencial atentar para o capital cultural e habitus de cada escola.

A partir do que fora apresentado por Bourdieu (1992; 1996; 1998; 2003a), Nogueira e Nogueira (2002), Setton (2002) e Hidalgo (2014), é possível afirmar que, na medida em que as condições sociais e históricas são alteradas, pode-se modificar o habitus e assim, as formas de pensar e agir dos sujeitos, porque existe o habitus primário, adquirido por meio da educação familiar e o secundário, metodicamente organizado pela educação escolar, podendo este último se sobrepor ao primeiro, se as práticas edificadas nas salas de aula oportunizarem tais mudanças. No entanto, de acordo com Bourdieu (1996) a escola tem atuado no modelo conservador, transformando em mérito escolar heranças culturais advindas do meio familiar, reproduzindo assim a ordem social já estabelecida.

Sobre a possibilidade de mudança na forma como a escola se organiza, Ribeiro (2004, p. 119) diz que,

A transformação da escola passa necessariamente pela transformação daqueles que trabalham dentro dela e que constituem um dos segmentos importantes para a vida da escola - os professores. [Para isso], A formação do professor hoje precisa estar em sintonia com o mundo em que vivemos. 
Azanha (2004, p. 373), também indica a necessidade de olhar para a formação de professores, porque "Não há dúvida de que o professor deve ser um profissional competente, [...] [mas ele precisa, sobretudo,] ser formado para enfrentar os desafios da novidade escolar contemporânea". Nesta perspectiva, é preciso que os profissionais atuantes na escola, em especial os professores, tenham clareza das suas incumbências na formação do sujeito, porque é preciso favorecer aos alunos a ampliação do capital cultural e mudança de habitus, tendo em vista o cumprimento das funções pedagógica e social. Assim sendo, "[...] os professores não podem ser aperfeiçoados abstratamente para o ensino da sua disciplina, mas para a tarefa coletiva do projeto de educar." (AZANHA,1998, p. 41).

\section{Construção do habitus docente no estágio curricular: uma possibilidade}

A formação de professores necessita ser pensada como um caminho que contemple um conjunto de ações intencionalmente planejadas para o exercício do ato de educar que consiste em,

[...] garantir aos alunos a apropriação do saber que eles não dominam quando chegam na escola. É na medida em que cumpre essa função que o professor se realiza como professor, que ele realiza, por assim dizer, a essência do seu ser enquanto professor [...] De posse desse saber que o professor, na escola, Ihes ensina, os alunos poderão desenvolver uma compreensão mais rigorosa e crítica da realidade em que vivem e, consequentemente, agir de forma mais consciente e eficaz para transformá-la. (SILVEIRA, 1995, p. 27).

Diante disso, torna-se essencial a atenção para a maneira como tem sido concretizado o estágio curricular nas instituições de ensino superior, devido à necessidade de favorecer a compreensão pelo futuro professor acerca de como se organiza a escola e a sala de aula (AZANHA, 1998, 2004; MOREIRA; CANDAU, 2003), tendo em vista captar suas especificidades e considerá-las no momento do planejamento e concretização da prática pedagógica. Nesta concepção de estágio, o mesmo deixa de ser reconhecido como o momento que visa à apropriação da prática para oportunizar uma visão mais ampliada do trabalho docente. Assim configurado o estágio, pouco a pouco, o estagiário vai entendendo a maneira como se estrutura o campo escolar, porque "Ao entrar em contato com a instituição educativa, descortina-se um emaranhado de relações que empurram sobremaneira a estagiária para si mesma." (OSTETTO, 2011, 
p. 88). O fato de estar na escola possibilita ao futuro professor tecer análises sobre o que fora nela vivenciado, instante em que recorre às teorias estudadas ao longo da graduação, seja para o reconhecimento dos fundamentos teóricos que embasam a ação docente dos professores atuantes no campo, ou para a compreensão de como o próprio campo se organiza.

E ainda, o exercício de análise das práticas pedagógicas efetivadas na escola pode favorecer o estagiário à identificação de suas próprias concepções, no que se refere ao embasamento teórico que dará suporte às suas ações, quando estiver no exercício da docência. Esse reconhecimento é essencial tendo em vista ressignificá-las, caso não oportunizem a ampliação do capital cultural e mudança do habitus dos estudantes que frequentam os anos iniciais do ensino fundamental. Para isso, o estágio curricular precisa ser planejado e concretizados de forma que possibilite,

[...] que a construção da identidade profissional do futuro professor seja pensada e elaborada não somente em relação à prática, mas envolvida num conjunto de ações que lhe permitirão ampliar os horizontes de sua compreensão e de sua atuação no campo de trabalho, orientando-se pela construção do conhecimento a partir de um processo sistemático e metódico de pesquisa. (GHEDIN; OLIVEIRA; ALMEIDA, 2015, p. 169).

Um processo de pesquisa que esteja centrado na realidade escolar, tendo em vista propiciar a construção do habitus docente, "[...] entendido como um conjunto de maneiras de atuar e de perceber a realidade na situação de ensino escolar. Espera-se que assim eles possam formular uma nova concepção de si, não mais como estudantes, e sim como professores." (NETO; SARTI; BENITES, 2016, p. 312).

Esse estudo, no intuito de expor ações realizadas no estágio curricular para promover a construção do habitus docente, apresenta o que evidencia Sarti (2013) no texto intitulado "Relações intergeracionais e alternância na formação docente: considerações a partir de uma proposta de estágio supervisionado", no qual expressa a configuração do estágio realizado no curso de Pedagogia da UNESP, campus de Rio Claro. Busca-se neste modelo de estágio estabelecer uma parceria entre o estagiário e os professores com experiência no magistério, sendo esses considerados como agentes de formação, um projeto que se desenvolve desde o ano de 2006 que por meio de um acordo estabelecido "[...] entre o curso de Pedagogia em questão e a Secretaria Municipal de Educação de Rio Claro. Cinco escolas da referida rede participam anualmente 
do projeto, sendo seus professores convidados a receber os estagiários e a atuar em sua formação." (p. 85).

A configuração desse estágio envolve o contato do estagiário com o professor regente, antes da entrada no campo, a partir de uma entrevista que visa a oportunizar ao futuro professor "[...] conhecer um pouco da trajetória e do perfil profissional do professor com o qual estabelecerá uma relação de parceria na docência, além de entrar em contato com a escola em que desenvolverá o estágio." (p. 85). Somente no semestre seguinte é que os estagiários irão para a escola, para desenvolver as 105 horas cumpridas com atividades diversas relativas à docência. Além disso, "Logo nas primeiras semanas do estágio, cada dupla, composta, por professor e estagiário, deverá elaborar um plano de trabalho conjunto para o período da parceria." (p. 85).

Compete aos supervisores de estágio, docente da universidade, realizar semanalmente, reuniões com os estagiários, momento em que os mesmos expõem as ações planejadas e executadas aos demais estagiários, aspecto que oportuniza a apreensão do ofício docente. No entanto, não são somente os estagiários que refletem sobre o ofício docente, pois os professores regentes são também convidados pelo supervisor para a participação em um curso de extensão universitária, tendo em vista "[...] enfatizar a importância do papel que os professores experientes desempenham nessa formação. Nos encontros que compõem o curso, os professores colaboradores são chamados a discutir, com seus pares e com a supervisora do estágio, suas experiências junto aos estagiários." (p. 86). A partir dessa ação, estagiários e professores elaboram um relatório, "[...] no qual são registrados os trabalhos e as experiências vividas durante a parceria docente." (p. 86),

\begin{abstract}
Para os estagiários, a elaboração dos registros requer um esforço de descentração, por meio do qual os mesmos deverão afastar-se de sua perspectiva discente para assumirem uma nova perspectiva, mais próxima à docência. [...] E os professores parceiros também exercem uma função importante na elaboração dos relatórios, oferecendo subsídios para que os estagiários ultrapassem suas concepções centradas em suas experiências como alunos e passem a considerar os eventos ocorridos no estágio a partir de uma perspectiva mais centrada na docência. (p. 86-87).
\end{abstract}

O estudo de Sarti (2013) é fruto da análise desses relatórios, “[...] compostos por uma parte principal, elaborada pelas duplas e, também, por um texto escrito individualmente, espaço em que professora e estagiária apresentam sua visão particular sobre a experiência vivida." (p. 87). Examinados a partir 
da análise de conteúdo, as falas das estagiárias contemplaram as percepções e aprendizagens obtidas no momento do estágio, porque possibilitou,

[...] perceber com maior clareza a diversidade de atividades, de imprevistos e de urgências que se impõem ao cotidiano docente. Puderam, ainda, partilhar com as professoras algumas das inseguranças e angústias que acompanham o trabalho docente na escola: as muitas e variadas metas a serem atingidas, a multiplicidade de projetos que por vezes se sobrepõem, o tempo fragmentado imposto pelo calendário escolar, os limites de recursos e de tempo para o trabalho com os alunos, etc. (p. 87-88).

Consta ainda nos relatos que a parceria possibilitou a partilha de aprendizagens profissionais e até o estabelecimento de laços afetivos entre estagiários e professores regentes. Além disso,

A docência em parceria mostrou-se, assim, um espaço propício para inovações, viabilizadas especialmente pela união entre a disposição (de tempo e de energia) das estagiárias e a perspicácia pedagógica das professoras envolvidas, todas elas experimentadas no magistério, atuando há mais de dez anos na docência. (p. 88).

Outro aspecto relevante se fez presente no discurso de professoras regentes, pois pelo fato de estarem há anos na docência essa atividade acaba sendo executada como corriqueira, sendo este sentido modificado no contato com as estagiárias, porque a vontade de aprender que elas demonstraram motivou as professoras regentes à busca de novidades no ensino. Segundo Sarti (2013),

[...] a parceria com uma professora experimentada possibilitava que as estudantes do curso de Pedagogia experimentassem o cotidiano escolar e da sala de aula a partir de um ponto de vista mais próximo da docência. Pouco a pouco, elas percebiam a existência de um 'modo docente' de considerar os alunos, a aprendizagem, os conteúdos do ensino, o calendário escolar, etc. (p. 89).

Fez-se presente também no relato das estagiárias que as professoras regentes pareciam adivinhar quando algo ia dar certo ou errado, sendo, portanto, suas intervenções essenciais nos planos de trabalho apresentados pelas futuras professoras, segundo elas as intervenções das professoras regentes 
foram de grande valia, porque com certeza teriam dificuldades para realizar o que fora planejado. (SARTI, 2013).

Aos poucos, as estagiárias percebiam que a inovação,
que tanto desejavam ver realizada durante o estágio, só
poderia ser viabilizada pelo envolvimento das professoras
experientes que, com seus saberes - sobre os alunos, o
programa, os pais, os outros professores, os recursos dis-
poníveis, etc. - possibilitavam que as ideias que traziam
sobre o ensino e para o ensino se transformassem em
efetivo trabalho docente. (p. 90 ).

Fica em evidência na fala das estagiárias o reconhecimento de uma certa criatividade por parte das professoras regentes, ao efetivarem suas práticas, pois segundo elas, essas professoras muitas vezes não segue a ordem estabelecida pelos programas escolares, organizando suas ações de maneira a favorecer a compreensão pelos alunos. Diante de tal aspecto, cabe recorrer a Certeau (1998, p. 38), pois "O cotidiano se inventa com mil maneiras de caça não autorizada.", porque se configura conforme as invenções pessoais do homem ordinário, produzindo assim um habitus, ou seja, uma determinada forma de agir.

Segundo Sarti (2013), nessa parceria entre estagiários e professores regentes ambos tiveram ganhos, porque os estagiários puderam: (a) conhecer mais de perto as atividades da docência, no cotidiano da escola; (b) solicitar ajuda à uma professora mais experiente e ainda (c) fazer análises conjuntas das ações efetivadas em sala de aula. Nesta forma de efetivar o estágio,

As muitas impressões que as estagiárias reuniam sobre o tra-
balho em sala de aula, os alunos e a escola podiam ser, assim,
discutidas com uma professora experiente. E esta passava a
contar, no ambiente comumente solitário da sala de aula, com
uma interlocutora especialmente interessada em suas opiniões,
mas cujos posicionamentos e questões tinham sido formulados a
partir de um ponto de vista de quem entra na profissão. (p. 92).

No que se refere aos ganhos obtidos pela professora regente, um deles se refere à reavaliação dos próprios pontos de vistas, acerca do ato de ensinar, de aprender e ainda a respeito do papel do aluno, visto que os questionamentos realizados pelas estagiárias demandaram da professora regente olhar para a própria prática e também buscar fundamentos teóricos que atendam às dúvidas das futuras professoras, 
Essa interlocução com uma "quase professora" requeria que a professora buscasse elaborar explicações, comentários, justificativas e, mesmo, novos questionamentos acerca desses assuntos. Esse modo de se (re)aproximar do próprio trabalho parece ter-lhes possibilitado experiências bastante formativas. A relação com as estagiárias parece tê-las deixado mais animadas para "continuar a aprender sempre". (SARTI, 2013, p. 92).

Segundo Sarti (2013), ao colaborarem na formação de futuros colegas de profissão, os professores regentes ocupam uma posição de destaque,

[...] o que thes traz sensação de reconhecimento e valorização profissional. [...] Para essas professoras, a presença das estagiárias representou importante estímulo para a experimentação e a diversificação na docência. [...] Ao acompanhar as práticas inaugurais das estagiárias, os professores experientes tornam-se suas companheiras, partilham sua sala de aula, seus conflitos, expectativas e perspectivas sobre o trabalho docente.

Realizado a partir de parceria, entre a escola e a universidade e entre os estagiários e as professoras regentes, o estágio curricular pode favorecer os futuros professores à passagem do habitus de aluno para o habitus docente, porque no contato com aquele profissional que já se encontra no exercício da profissão tem a oportunidade de conhecer como se organiza o campo escolar, em especial o cotidiano da sala de aula. Além disso, pode também possibilitar mudanças no habitus dos agentes que compõem a escola, a partir dos questionamentos realizados pelos estagiários, aspecto que acaba por impulsionar o professor regente à revisão das próprias concepções, no que se diz respeito à função da escola e do professor na construção do sujeito, já que conforme indicam estudiosos do tema precisa proporcionar avanços pedagógicos (SAVIANI, 1995; VIEIRA; ALMEIDA, 200-; RAMOS; LEITE; FILHO, 2012) e sociais (ARROYO, 1986; VIEIRA; ALMEIDA, 200-), o que consiste em minimizar as desigualdades sociais a partir do aumento do capital cultural de todos os alunos, em especial dos estudantes provenientes de classes sociais menos favorecidas (BOURDIEU, 1998).

Nota-se, portanto, que o contato com professores em ação possibilita situações de coaprendizagem, propiciando a construção de novos conhecimentos a ambos, professores regentes e estagiários, quando se fomenta o diálogo e a valorização do conhecimento do outro. Deste modo, ou seja, por meio 
do confronto dialético, é possível construir novos saberes docentes, sendo o conhecimento resultado das experiências vivenciadas em sala de aula, de maneira crítica, pela qual, professores atuantes e aqueles ainda em formação são parceiros na sua produção. Fica evidente, por conseguinte, a importância de se criar espaços para a produção de conhecimentos docentes no estágio curricular, tendo em vista gerar novas teorias que possibilitem aos professores em exercício e em formação, intervir de forma adequada na prática pedagógica, com a finalidade de propiciar a ampliação dos conhecimentos dos educandos.

\section{Considerações finais}

O estágio curricular representa a oportunidade do professor em formação, ingressar na cultura da carreira docente, conhecendo o cotidiano da sua profissão e posicionando-se sobre ela. A escola, como agência de socialização, contribui para novas configurações culturais, assim, o conceito de habitus possibilita refletir sobre a identidade dos sujeitos que constitui a educação institucionalizada, a partir de condicionamentos sociais. É a partir da relação dialética, entre indivíduo e sociedade, que se considera a realidade da profissão no mundo contemporâneo.

A pesquisa bibliográfica teve como objetivo apresentar uma experiência realizada no estágio curricular que contribui na construção do habitus docente, para isso, partiu-se das contribuições da teoria do habitus de Bourdieu. A preocupação é que a formação propiciada pelo estágio possa promover mudanças nas práticas cotidianas dos professores e, que cada vez mais, os mesmos se conscientizem da importância do contínuo estudo, sabendo que existe uma relação entre o aprender, o ensinar e a mudança de sua prática em sala de aula. Então, deve-se frisar que o professor precisa aprender constantemente, se sua intenção é a de ensinar de forma a favorecer a melhoria da aprendizagem do aluno, pois é este o papel, como educador, desenvolver ações que favoreçam ações colaborativas entre os estudantes e ao acompanhamento dos seus avanços e dificuldades, porque se faz necessário atuar sobre elas. Para isso, o ensino precisa ser encarado pelo professor como um processo de ajuda e de direcionamento da aprendizagem. Deve, ainda, provocar desafios que conduzam o aluno à transformação do conhecimento.

Partindo do pressuposto de que o paradigma pós-moderno é de transição, sua epistemologia concebe o professor como mediador da aprendizagem, seus pressupostos estão fundamentados em uma epistemologia que interpreta o professor como construtor de seus conhecimentos, face à interação com uma 
realidade que vai sendo construída pelas representações que esses professores fazem de suas experiências profissionais e pessoais. Assim, as estruturas sociais que constituem o habitus docente, permitem evidenciar que a identidade do professor se constrói ao longo da sua profissão e o estágio curricular interfere na sua formação. A partir disso, é possível inferir que a troca dialógica entre professores em exercício e futuros professores é riquíssima. Ensinar e aprender são processos de mediação, e o conceito de ensinar pode ser reelaborado pelo desenvolvimento de atividades colaborativas e estratégias interativas entre eles, o que determinam as formas identitárias desses professores, atuantes e em formação. Convém destacar a importância do estudo da gênese que constitui a base do habitus docente e a sua relação com o futuro campo de trabalho do professor em formação, tendo em vista criar um campo de significação com ricas informações à este momento da formação inicial.

\section{Referências}

ARIÈS, Philippe. História social da criança e da família. 2a edição. Rio de Janeiro: Editora Afiliada, 1978.

ARROYO, Miguel G. A escola possível é possível? In: ARROYO, M.G (org). Da escola carente à escola possível. São Paulo: Ed. Loyola.1986, p.11-53.

AZANHA, José Mario Pires. Proposta Pedagógica e autonomia da escola. Cadernos de História e Filosofia da Educação, v. 2, n. 4p. 32-48, 1998. Disponível em: http://www3.fe.usp.br/secoes/inst/novo/acervo_jmpa/PDF_SWF/78. pdf.

AZANHA, José Mario Pires. Uma reflexão sobre a formação do professor da escola básica, Educação e Pesquisa, São Paulo, v.30, n.2, p. 369-378, maio/ ago, 2004. Disponível em http://www.scielo.br/scielo.php?script=sci_arttext\&pid=S1517-97022004000200016. Acesso em: 14 abr. 2016.

BAUMAN, Zygmunt. Vidas desperdiçadas. Rio de Janeiro: Jorge Zahar, 2005.

BOURDIEU, Pierre. A economia das trocas simbólicas. São Paulo: Perspectiva, 1992.

BOURDIEU, Pierre. O novo capital. In BOURDIEU, Pierre. Razões práticas sobre a teoria da ação. Tradução Mariza Corrêa. São Paulo: Papirus, 1996. p. 35-52. Disponível em:

http://disciplinas.stoa.usp.br/pluginfile.php/347738/mod_resource/con- 
tent/1/BOURDIEU\%2C\%20P.\%20Raz\%C3\%B5es\%20Pr\%C3\%A1ticas\%20-\%20 Sobre\%20a\%20Teoria\%20da\%20A\%C3\%A7\%C3\%A3o.pdf. Acesso em: 03. Fev. 2016.

BOURDIEU, Pierre. A escola conservadora: as desigualdades frente à escola e à cultura. In: NOGUEIRA, Maria Alice; CATANI, Afrânio (Orgs.). Escritos de Educação. Petrópolis: Vozes, 1998, p. $39-64$.

BOURDIEU, Pierre. Obras culturais e disposição culta. In: BOURDIEU, Pierre; DARBEL, Alain. $O$ amor pela arte - os museus de arte na Europa e seu público. Tradução de Guilherme João de Freitas Teixeira. São Paulo: Edusp/Zouk, 2003a. p. 69-111.

BOURDIEU, Pierre. A dominação masculina. 3 ed. Rio de Janeiro: Bertrand Brasil, 2003b.

BOURDIEU, Pierre; PASSERON, Jean-Claude. Les héritiers: les étudiants et la culture. Paris: Les Éditions de Minuit, 1964.

CARVALHO, Luciano de Souza. O Capital Cultural na construção de uma Educação Democrática, Reflexiva e Libertadora, Revista Thema, Pelotas, v. 9, n. 2, 2012, p. 1-16. Disponível em: file://F:/\%23Mari/Downloads/144-411-1-PB. pdf. Acesso em: 11 abr. 2016.

CERTEAU, Michel de. Invenção do Cotidiano: artes de fazer. 3a ed. Petropolis: Vozes, 1998.

FREIRE, Paulo. Pedagogia do oprimido. Rio de Janeiro: Paz e Terra, 1987. Disponível em: http://www.dhnet.org.br/direitos/militantes/paulofreire/paulo_freire_pedagogia_do_oprimido.pdf. Acesso em: 02. abr. 2016.

GHEDIN, Evandro, OLIVEIRA, Elisangela S. de; ALMEIDA, Whasgthon A. de Almeida. Estágio com pesquisa. São Paulo: Cortez, 2015.

Gil, Antônio Carlos. Métodos e técnicas de pesquisa social. 5. ed. São Paulo: Atlas, 1999.

HIDALGO, Kênia Ribeiro da Silva. Fracasso escolar: uma violência simbólica na perspectiva sociológica de Bourdieu, Publ. UEPG Ci. Soc. Apl., Ponta Grossa, v. 22, n. 2, p. 193-204, jul./dez. 2014. Disponível em:

http://www.revistas2.uepg.br/index.php/sociais/article/viewFile/6045/4227. Acesso em: 01. Abr. 2016.

MOREIRA, Antonio Flavio Barbosa; CANDAU, Vera Maria. Educação escolar e 
cultura(s): construindo caminhos. Revista Brasileira de Educação, Rio de Janeiro, n. 23, p. 156-167, mai./ago. 2003. Disponível em: http://www.scielo. $\mathrm{br} / \mathrm{pdf} / \mathrm{rbedu} / \mathrm{n} 23 / \mathrm{n} 23 a 11$. Acesso em: 02 fev. 2016.

NETO, Samuel de Souza, SARTI, Flavia Medeiros, BENITES, Larissa Cerignoni. Entre o ofício de aluno e o habitus de professor: os desafios do estágio supervisionado no processo de iniciação à docência, Movimento, Porto Alegre, v. 22, n. 1, p. 311-324, jan./mar. 2016. Disponível em: http://www.seer.ufrgs.br/ index.php/Movimento/article/view/49700/36619. Acesso em: 07 ago. 2016.

NOGUEIRA, Maria Alice; NOGUEIRA, Cláudio Marques Martins. A sociologia da educação de Pierre Bourdieu: limites e contribuições. Educação \& Sociedade, ano XXIII, n. 78, Abr., 2002, p. 15-36. Disponível em: http://www.scielo. br/pdf/es/v23n78/a03v2378.pdf. Acesso em: 22 fev. 2016.

NOGUEIRA, Maria Alice. Um arbitrário cultural dominante. Revista Brasileira de Educação. maio/ago, n. 23. Campinas: Editora Autores Associados, 2003.

OSTETTO, Luciana Esmeralda. Deslocamentos, aproximações, encontros: estágio docente na educação infantil. Em: GOMES, Marineide de Oliveira. Estágios na formação de professores: possibilidades formativas entre ensino, pesquisa e extensão. São Paulo: Edições Loyola, 2011, p. 79-98.

PATTO, Maria Helena de Souza. Formação de professores: o lugar das humanidades. In: BARBOSA, Raquel Lazzari Leite. Trajetórias e perspectivas da formação de professores. São Paulo: Editora UNESP, 2004, p. 61- 78.

PEREIRA, G. M.; ANDRADE, M. C. L. Coach Carter ou a segunda chance dos excluídos do interior. Revista Brasileira de Ciência, p.56-65, 2007.

RAMOS, Jeannette F. Pouchain; LEITE, Adriana Antero; FILHO, Luciano de A. Filgueiras. Função social da escola: qual o lugar do pedagógico, do político e do trabalho?. 2012. Disponível em: http://educas.com.br/blog/wp-content/ uploads/2012/04/FUN\%C3\%87\%C3\%830-SOCIAL-DA-ESCOLA.pdf. Acesso em: 26 mar. 2016.

RIBEIRO, Ricardo. Dez princípios sobre professores e formação de professores. In: BARBOSA, Raquel Lazzari Leite (Org.). Trajetórias e perspectivas da formação de professores. São Paulo: Editora UNESP, 2004, p. 117-126.

RODRIGUES, Neidson. Da mistificação da escola à escola necessária. 6ạ. Edição. São Paulo: Cortez, 1992.

SARTI, Flávia. Relações intergeracionais e alternância na formação docente: considerações a partir de uma proposta de estágio supervisionado, Pelotas, 
n. 46, p. 83-99 set./dez. 2013. Disponível em: file:///F:/\%23Mari/Downloads/4174-10735-1-PB.pdf. Acesso em: 08 ago. 2016.

SAVIANI, Dermeval. Escola e Democracia: teorias da educação, curvatura da vara, onze teses sobre educação política. Coleção Polêmicas do Nosso Tempo. 29ạ edição, Campinas: Autores Associados, 1995.

SAVIANI, Dermeval Formação de professores no Brasil: dilemas e perspectivas. Em: Poíesis Pedagógica, v.9, n.1, p. 07-19, jan./jun. 2011. Disponível em: <file:///F:/\%23Mari/Downloads/15667-63261-1-PB.pdf>. Acesso em: 07 abr. 2016.

SETTON, Maria da Graça Jacintho Setton. A teoria do habitus em Pierre Bourdieu: uma leitura contemporânea. Revista Brasileira de Educação, n. 20, p. 60-70, mai./ago, 2002. Disponível em: http://www.scielo.br/pdf/rbedu/n20/ n20a05. Acesso em 2 fev. 2016.

SILVEIRA, R. J. T. O professor e a transformação da realidade. Nuances - Revista do Curso de Pedagogia, Faculdade de Ciências e Tecnologia- UNESP, Presidente Prudente, v. 1, n. 1, p. 21-30, set. 1995.

VIEIRA, Vera Lucia Marschall; ALMEIDA, Janaina Aparecida Mattos de. A função social da escola pública: a especificidade do trabalho na sala de aula. 200-. Disponível em: http://www.diaadiaeducacao.pr.gov.br/portals/pde/arquivos/2387-8.pdf. Acesso em: 01 fev. 2016. 